\title{
Effect of replacing maize silage with red clover silage in the diet on milk fatty acid composition in cows
}

\author{
Franziska Schulz, ${ }^{*}$ Edwin Westreicher-Kristen, ${ }^{* 1}$ Joachim Molkentin, $†$ Karin Knappstein, $\dagger$ \\ and Andreas Susenbeth* \\ *Institute of Animal Nutrition and Physiology, Christian-Albrechts-Universität zu Kiel, 24118 Kiel, Germany \\ †Department of Safety and Quality of Milk and Fish Products, Max Rubner-Institute, 24103 Kiel, Germany
}

\begin{abstract}
This study aimed to evaluate the effect of replacing maize silage plus soybean meal with red clover silage (RCS) plus wheat on the fatty acid (FA) profile in the milk fat of cows. Forty-four lactating German Holstein cows were used in a $4 \times 4$ Latin square design with 21-d periods composed of $13 \mathrm{~d}$ of adaptation to diets followed by an 8-d sampling phase. Experimental diets offered as total mixed ration consisted of a constant forage-to-concentrate ratio (75:25) with target proportions of RCS to maize silage of 15:60 $\left(\mathrm{RCS}_{15}\right)$, 30:45 $\left(\mathrm{RCS}_{30}\right), 45: 30\left(\mathrm{RCS}_{45}\right)$, and 60:15 $\left(\mathrm{RCS}_{60}\right)$ on a dry matter basis. Increasing the level of RCS in the diet was accompanied by a reduction of linoleic acid content in the diet and decreased linearly the proportions of linoleic acid in the milk up to $4 \%$. Proportions of $\alpha$-linolenic acid in milk increased 2-fold with $\mathrm{RCS}_{60}$ compared with $\mathrm{RCS}_{15}$, which resulted from the linear increase in $\alpha$-linolenic acid intake with incremental levels of RCS. Vaccenic acid in the milk fat was reduced by $24 \%$. Rumenic acid, a conjugated linoleic acid (cis9,trans-11 conjugated linoleic acid) considered to be a human health promoter, was also decreased by $22 \%$. Reduced rumenic acid in the milk fat was probably due to a reduced amount of vaccenic acid produced in the rumen and, consequently, to the low amount of vaccenic acid to be desaturated to rumenic acid in the mammary gland by $\Delta^{9}$-desaturase. Oleic acid was enriched in the milk fat, although the dietary concentration of oleic acid decreased. Stearic acid proportions remained constant with increasing levels of RCS. The proportions of total polyunsaturated FA were increased by $12 \%$, and the long-chain FA proportions increased linearly with increasing levels of RCS. Myristic acid was reduced linearly, but palmitic acid remained constant. Saturated
\end{abstract}

Received December 22, 2017.

Accepted April 12, 2018.

${ }^{1}$ Corresponding author: westreicher@aninut.uni-kiel.de
FA was reduced linearly by $2 \%$. Branched-chain FA, which are presumed to possess anticarcinogenic properties, were reduced to a small extent only (quadratic effect). We conclude that replacing maize silage with RCS appears to alter milk FA composition by reducing linoleic acid intake and ruminal biohydrogenation. Feeding RCS represents a strategy to increase intake of $\alpha$-linolenic acid in dairy cows. However, because changes in the FA profile show positive as well as negative effects, no distinct conclusions can be drawn with regard to human health benefits.

Key words: red clover, biohydrogenation, polyunsaturated fatty acid, fatty acid profile

\section{INTRODUCTION}

Cow milk fat is the most variable milk component, in concentration and composition (Palmquist, 2006), and consists predominantly of triglycerides (Bauman and Griinari, 2003). The fatty acids (FA) in milk fat are either synthesized de novo in the mammary gland or taken up from the blood; FA in the blood originate largely from the diet and partially from microbial lipid metabolism in the rumen as well as from mobilized body fat reserves (Bauman and Griinari, 2003). Although diets of dairy cows are generally high in UFA, milk fat consists mainly of SFA, which is partly due to extensive microbial biohydrogenation (BH) of dietary UFA in the rumen (Shingfield et al., 2010). From a human health point of view, it would be desirable to decrease the SFA content, especially concentrations of medium-chain SFA, and to increase the PUFA content in milk fat (Lock and Bauman, 2004; Dewhurst et al., 2006). The PUFA of particular interest are linoleic acid (LA, cis-9, cis-12 C18:2), $\alpha$-linolenic acid ( $\boldsymbol{\alpha - L N A}$, cis-9,cis-12,cis-15 C18:3), and rumenic acid (RA, cis9,trans-11 C18:2) that represents the primary isomer of CLA in milk.

Because BH of PUFA in the rumen decisively influences the composition of milk fat, reducing to a certain extent the $\mathrm{BH}$ in the rumen or increasing the supply of 
PUFA to improve the amount that escape BH represent alternative approaches to enhance the nutritional quality of milk fat of cows for human diets. Red clover (Trifolium pratense $\mathrm{L}$.) is one of the most important forage legumes for silage production in northern Europe and North America (Moorby et al., 2016). Several studies have shown enhanced concentrations of total PUFA, LA, and $\alpha$-LNA in milk fat of cows when feeding red clover silage (RCS) compared with grass silage (Dewhurst et al., 2003a; Moorby et al., 2009; Halmemies-BeauchetFilleau et al., 2014). This effect is generally linked to the polyphenol oxidase (PPO) activity present in red clover (Van Ranst et al., 2011; Lee, 2014). Because of a reduction in lipolysis and subsequent $\mathrm{BH}$ in the rumen, a higher escape of dietary PUFA from the rumen may occur when feeding RCS (Halmemies-Beauchet-Filleau et al., 2013). However, RCS is characterized by relatively high-CP and low-energy contents. Maize silage (MZS) is a significant source of rapidly fermentable carbohydrates, has low CP content, and, therefore, is a good complement to RCS. In line with this, some studies demonstrated improvements in feed intake and milk production when feeding RCS-MZS mixtures compared with RCS as the sole forage source (Broderick et al., 2001; Hoffman and Bauman, 2003). In contrast, Schulz et al. (2018) found reduced DMI and milk yield when replacing MZS with RCS in diets of cows. However, to our knowledge, no published study so far exists that examined the effect of feeding different dietary ratios of RCS to MZS on the milk FA profile of cows. Red clover silage provides a source of homegrown protein, MZS is highly important as a forage on dairy farms, and consumer awareness of the potential health benefits of some milk FA is increasing; therefore, an evaluation of the effects of different proportions of RCS and MZS on FA profile of cow milk is required.

The aim of the present study was to evaluate the effect of replacing MZS with RCS in the diet on milk FA composition of cows, with special focus on the FA related to ruminal $\mathrm{BH}$ and promoters of human health: LA, $\alpha$-LNA, RA, vaccenic acid (VA, trans-11 C18:1), stearic acid (SA, C18:0), myristic acid (MA, C14:0), and oleic acid (OA, cis-9 C18:1). We hypothesized that increasing levels of RCS in diets of cows would improve the quality of milk FA profile.

\section{MATERIALS AND METHODS}

\section{Animals, Diets, and Experimental Design}

The study reported herein was performed in accordance with the German Animal Welfare Act (Federal Republic of Germany, 2014) and approved by the Animal Welfare Commission of the Ministry of Energy, Agriculture, the Environment and Rural Areas of the federal state of Schleswig-Holstein, Germany (V 242-72241.123-5). The feeding experiment was carried out with 44 German Holstein cows at the experimental farm Schädtbek of the Max Rubner-Institute (Dobersdorf, Germany). Cows were randomly assigned to 4 groups according to milk yield, DIM, lactation number, and BW, averaging (mean \pm SD) $38.7 \pm 7.3 \mathrm{~kg} / \mathrm{d}, 149$ $\pm 103 \mathrm{~d}, 1.9 \pm 1.1$, and $624 \pm 52 \mathrm{~kg}$ at the start of the experiment, respectively.

Red clover ('Harmonie') and maize (Zea mays 'Amagrano,' 'LG 30.222,' and 'Saludo') were grown as pure stands. Detailed information about the preparation of RCS and MZS are described by Schulz et al. (2018). The 4 experimental diets offered as TMR consisted of a constant forage-to-concentrate ratio $(75: 25$ on a DM basis) with targeted proportions of RCS to MZS in diet DM of 15:60 $\left(\mathbf{R C S}_{15}\right), 30: 45\left(\mathbf{R C S}_{30}\right), 45: 30$ $\left(\mathbf{R C S}_{45}\right)$, and 60:15 $\left(\mathbf{R C S}_{60}\right)$. All diets contained (on a DM basis) on average $8.8 \%$ ground lupine seeds and $16 \%$ soybean meal plus ground wheat in different ratios to obtain isonitrogenous diets. The proportion of lupine seeds was similar across diets to avoid an effect on the milk FA profile due to its relatively high content of ether extract. Ingredients and chemical composition of the 4 experimental diets are presented in Table 1. Diets were offered once daily at approximately $0600 \mathrm{~h}$ for ad libitum consumption. Cows were kept in a freestall barn equipped with cubicles bedded with chopped straw and had free access to water. Cows were housed and fed per group (4 groups of 11 cows each). Animal:feeding place ratio and animal:cubicle ratio were both 1:1. The design of the experiment was a $4 \times 4$ Latin square. Each experimental period comprised $21 \mathrm{~d}$ with a $13-\mathrm{d}$ adaption phase followed by an 8-d sampling phase.

\section{Sampling, Recordings, and Chemical Analyses}

Diets. Details on diet sampling and analysis of DM, crude ash, ether extract, CP, starch, sugar, NDF, ADF, and ADL concentrations are described by Schulz et al. (2018). Fatty acid compositions of diets were analyzed according to the official analytical methods in Germany (DGF, 2015) by LUFA-ITL GmbH (Kiel, Germany). Fatty acid methyl esters were obtained by transesterification (method C-VI 11a) without prior fat extraction. For this purpose 1 to $2 \mathrm{~g}$ of feed sample and $4 \mathrm{~mL}$ of a $0.5 \mathrm{~mol} / \mathrm{L}$ solution of potassium hydroxide in methanol were mixed in a $50-\mathrm{mL}$ round-bottom flask and heated under reflux to the boiling point. After addition of $5 \mathrm{~mL}$ of a solution of boron trifluoride (wt $=12-15$ $\mathrm{g} / 100 \mathrm{~g}$ ) in methanol, the sample was boiled for $3 \mathrm{~min}$. 
After cooling to room temperature, $5 \mathrm{~mL}$ of isooctane was added to the sample. While shaking the flask, a saturated solution of sodium chloride was added until the liquid level filled the flask neck. The sample was allowed to stand until phase separation occurred. Approximately 1 to $2 \mathrm{~mL}$ of the upper isooctane phase, containing about $20 \mathrm{mg}$ of FAME/mL, was transferred in a sample vial and dried with anhydrous sodium sulfate. The supernatant was further diluted with isooctane to $0.5 \mathrm{mg}$ of $\mathrm{FAME} / \mathrm{mL}$ for the subsequent determination of FA composition by GC (method C-VI 10a). For this, $1 \mu \mathrm{mol}$ of the FAME solution was injected into an Agilent 7890A gas chromatograph equipped with a flame ionization detector and a $50 \mathrm{~m} \times 0.25$ inside diameter fused-silica capillary column coated with 20 $\mu \mathrm{m}$ of film of CP-Sil 88 (Agilent Technologies, Santa Clara, CA). Hydrogen was used as carrier gas operated at a flow rate of $1.5 \mathrm{~mL} / \mathrm{min}(\sim 100 \mathrm{kPa}$ initial pressure). Injector and detector temperatures were 230 and $250^{\circ} \mathrm{C}$, respectively. The oven temperature was held at $50^{\circ} \mathrm{C}$ for 2 min before being increased at $4^{\circ} \mathrm{C} / \mathrm{min}$ to $100^{\circ} \mathrm{C}$. Thereafter, the temperature was programmed to increase at $6.5^{\circ} \mathrm{C} / \mathrm{min}$ to $165^{\circ} \mathrm{C}$, followed by an increase at $13^{\circ} \mathrm{C} / \mathrm{min}$ to $190^{\circ} \mathrm{C}$, which was then held for $7 \mathrm{~min}$ isothermal. To identify individual FA, the Supelco 37 component FAME mix (product number CRM 47885; Sigma-Aldrich Chemie GmbH, Steinheim, Germany) was used as reference standard. Additionally, the reference fat BCR 163 (IRMM, Geel, Belgium) was used as the control sample. Fatty acids in the range of $\mathrm{C} 8$ to

Table 1. Ingredients and chemical composition of the experimental diets ${ }^{1}$

\begin{tabular}{|c|c|c|c|c|}
\hline Item & $\mathrm{RCS}_{15}$ & $\mathrm{RCS}_{30}$ & $\mathrm{RCS}_{45}$ & $\mathrm{RCS}_{60}$ \\
\hline \multicolumn{5}{|l|}{ Ingredient, $\%$ of DM } \\
\hline Red clover silage & 13.6 & 27.5 & 42.1 & 57.1 \\
\hline Maize silage & 61.0 & 46.6 & 31.6 & 16.2 \\
\hline Lupine seeds & 8.59 & 8.70 & 8.88 & 8.96 \\
\hline Soybean meal & 15.9 & 10.8 & 5.50 & - \\
\hline Wheat grain & - & 5.49 & 11.0 & 16.8 \\
\hline Premix $^{2}$ & 0.91 & 0.91 & 0.92 & 0.94 \\
\hline \multicolumn{5}{|l|}{ Chemical composition, $\%$ of DM } \\
\hline $\mathrm{OM}$ & 94.0 & 92.9 & 91.6 & 90.7 \\
\hline $\mathrm{CP}$ & 17.2 & 17.4 & 17.3 & 17.5 \\
\hline Ether extract & 2.14 & 2.13 & 2.05 & 2.02 \\
\hline Starch & 23.2 & 20.5 & 18.0 & 17.0 \\
\hline Sugar & 5.62 & 2.93 & 2.51 & 2.84 \\
\hline NDF & 34.7 & 34.0 & 35.2 & 35.3 \\
\hline $\mathrm{ADF}$ & 21.9 & 22.5 & 24.5 & 25.2 \\
\hline ADL & 2.80 & 3.24 & 3.69 & 4.10 \\
\hline \multicolumn{5}{|l|}{ Fatty acids (FA), g/100 g of FA } \\
\hline $\mathrm{C} 12: 0$ & 0.2 & 0.2 & 0.2 & 0.2 \\
\hline C14:0 (myristic acid) & 0.4 & 0.6 & 0.8 & 1.0 \\
\hline C16:0 (palmitic acid) & 17.3 & 17.9 & 18.9 & 20.1 \\
\hline cis-9 C16:1 & 0.5 & 0.8 & 1.2 & 1.5 \\
\hline C18:0 (stearic acid) & 3.8 & 3.9 & 3.8 & 4.0 \\
\hline cis-9 C18:1 (oleic acid) & 20.8 & 18.8 & 15.0 & 12.6 \\
\hline cis-11 C18:1 & 0.8 & 0.8 & 0.6 & 0.6 \\
\hline cis-9,cis-12 C18:2 (linoleic acid) & 42.6 & 39.0 & 34.1 & 30.0 \\
\hline cis-9,cis-12,cis-15 C18:3 ( $\alpha$-linolenic acid $)$ & 9.7 & 13.7 & 20.4 & 25.2 \\
\hline $\mathrm{C} 20: 0$ & 0.8 & 0.9 & 0.9 & 1.1 \\
\hline cis-11 C20:1 & 0.4 & 0.4 & 0.4 & 0.5 \\
\hline C22:0 & 0.9 & 1.0 & 1.0 & 1.2 \\
\hline $\mathrm{C} 24: 0$ & 0.7 & 0.8 & 0.9 & 0.2 \\
\hline $\mathrm{SFA}^{3}$ & 24.6 & 25.8 & 27.3 & 28.7 \\
\hline MUFA $^{4}$ & 22.6 & 20.8 & 17.3 & 15.5 \\
\hline $\mathrm{PUFA}^{5}$ & 52.4 & 52.9 & 55.0 & 55.6 \\
\hline
\end{tabular}

${ }^{1}$ Diets were composed of forage and concentrates (75:25), with targeted levels of red clover silage (RCS) in the TMR of $15 \%\left(\mathrm{RCS}_{15}\right), 30 \%\left(\mathrm{RCS}_{30}\right), 45 \%\left(\mathrm{RCS}_{45}\right)$, and $60 \%\left(\mathrm{RCS}_{60}\right)$ on a DM basis.

${ }^{2}$ Composed of $0.3 \%$ salt and the rest of a mineral-vitamin premix. Composition of the mineral-vitamin premix (in $\mathrm{kg}$ of fresh matter and according to manufacturer specifications): $200 \mathrm{~g}$ of $\mathrm{Ca}, 80 \mathrm{~g}$ of $\mathrm{Na}, 40 \mathrm{~g}$ of $\mathrm{Mg}, 40$ $\mathrm{g}$ of P, 8,000 $\mathrm{mg}$ of $\mathrm{Zn}, 6,400 \mathrm{mg}$ of $\mathrm{Mn}, 1,200 \mathrm{mg}$ of Cu, $160 \mathrm{mg}$ of I, $70 \mathrm{mg}$ of Co, $45 \mathrm{mg}$ of Se, 5,000 mg of vitamin E, 1,250,000 IU of vitamin A, and 125,000 IU of vitamin D.

${ }^{3} \mathrm{Sum}$ of all FA without double bonds.

${ }^{4}$ Sum of all FA with one double bond.

${ }^{5}$ Sum of all FA with more than one double bond. 
C24 were determined and calculated as weight percentage $(\mathrm{g} / 100 \mathrm{~g}$ of FA). The detection limit of FA was less than $0.1 \mathrm{~g} / 100 \mathrm{~g}$ of FA.

Milk. Cows were milked twice daily starting at 0500 and $1430 \mathrm{~h}$. During the sampling phase of each period, the milk yield of individual cows was recorded at each milking by using calibrated electronic milk meters (Metatron P21, GEA Farm Technologies GmbH, Bönen, Germany). Samples of milk were collected from each cow once daily, alternating between morning and afternoon milking, from d 14 to 21 and stored at $-20^{\circ} \mathrm{C}$. At the end of each period, frozen milk samples were thawed overnight at $4^{\circ} \mathrm{C}$ and homogenized in a water bath at $38^{\circ} \mathrm{C}$ for $20 \mathrm{~min}$. Afterward, milk samples were pooled per cow according to the milk yield at individual milkings and stored at $-20^{\circ} \mathrm{C}$ until analysis. Milk fat fraction was extracted according to the Röse-Gottlieb-method (IDF, 2010) without fat quantification as described by Castro-Montoya et al. (2016). Fatty acid methyl esters were obtained from the extracted milk fat by transesterification using methanolic potassium hydroxide (IDF, 2002a). Subsequently, FA composition was determined by GC (IDF, 2002b) as described by Castro-Montoya et al. (2016), using a 60 $\mathrm{m} \times 0.25$ inside diameter fused-silica capillary column coated with a $20-\mu \mathrm{m}$ film of CP-Sil 88 (Agilent Technologies). The reference milk fat CRM 164 (IRMM) was used for calibration of the major FA. Fatty acids were determined in the range of $\mathrm{C} 4: 0$ to $\mathrm{C} 24: 0$ and expressed as weight percentage $(\mathrm{g} / 100 \mathrm{~g}$ of detected FA). Analyzed FA were classified according to the degree of saturation in SFA (no double bonds), MUFA (with one double bond), and PUFA (with more than one double bond). The group of UFA was defined as the sum of MUFA and PUFA. Based on carbon chain length, FA were categorized in short-chain FA (SCFA, C4:0-C10: 0), medium-chain FA (MCFA, C11:0-C17:0), and long-chain FA (LCFA, C18:0-C24:0), with all 3 groups including SFA and UFA. Branched-chain FA (BCFA) were defined as the sum of iso $\mathrm{C} 13: 0$, iso $\mathrm{C} 14: 0$, iso $\mathrm{C} 15: 0$, iso $\mathrm{C} 16: 0$, iso $\mathrm{C} 17: 0$, iso $\mathrm{C} 18: 0$, anteiso $\mathrm{C} 13: 0$, anteiso $\mathrm{C} 15: 0$, and anteiso $\mathrm{C} 17: 0$. The $\mathrm{n}-3 \mathrm{FA}$ were defined as the sum of cis-15 C18:1; $\alpha$-LNA; cis-5,cis8,cis-11,cis-14,cis-17 C20:5 (EPA, eicosapentaenoic acid); and cis-7,cis-10,cis-13,cis-16,cis-19 C22:5 (DPA, docosapentaenoic acid).

The n-6 FA were defined as the sum of cis-12 C18:1; LA; cis-6,cis-9,cis-12 C18:3; cis-11,cis-14 C20:2; cis8,cis-11,cis-14 C20:3 (ETE, eicosatrienoic acid), and cis-5, cis-8,cis-11,cis-14 C20:4 (ARA, arachidonic acid). To determine the $\Delta^{9}$-desaturase activity (DA) in the mammary gland, the ratios of $\Delta^{9}$-desaturase product to $\Delta^{9}$-desaturase precursor were calculated as DA C10 $=$ cis-9 C10:1/C10:0, DA C12 = cis-9 C12:1/C12:0, and DA C14 = cis-9 C14:1/C14:0.

\section{Statistical Analyses}

All data were statistically analyzed using the software $\mathrm{R}$ (version 3.1.1, The R Foundation for Statistical Computing, Vienna, Austria). Data were approximately normally distributed and homoscedastic, proven by a graphical residual analysis. An arithmetic mean per cow and period was calculated and used for statistical analyses. The following statistical mixed model was used:

$$
Y_{i j k l}=\mu+P_{i}+G_{j}+C_{k(\mathrm{j})}+T_{l}+e_{i j k l},
$$

where $Y_{i j k l}$ is the dependent variable, $\mu$ is the overall mean, $P_{i}$ is the random effect of period $i(i=1$ to 4$)$, $G_{j}$ is the random effect of group $j(j=1$ to 4$), C_{k(j)}$ is the random effect of cow $k$ (within group $j ; k=1$ to 11 ), $T_{l}$ is the fixed effect of dietary treatment $l(l=1$ to 4$)$, and $e_{i j k l}$ is the random residual error.

Data were analyzed by ANOVA to identify treatment effects. Multiple contrast tests related to Tukey were conducted for treatment comparisons. In addition, orthogonal polynomial contrasts were used to test for linear and quadratic effects of RCS on FA concentrations. All reported values are least squares means. Significance was declared at $P<0.05$, and tendencies were declared with $P$-values between 0.05 and 0.10.

\section{RESULTS}

\section{FA Composition of Diets}

The FA profile varied considerably among diets when increasing the level of RCS (Table 1). The concentrations of SFA and PUFA increased from 24.6 to 28.7 $\mathrm{g} / 100 \mathrm{~g}$ and from 52.4 to $55.6 \mathrm{~g} / 100 \mathrm{~g}$ of FA, respectively. Concurrently, the concentrations of MUFA decreased from 22.6 to $15.5 \mathrm{~g} / 100 \mathrm{~g}$ of total FA. The major FA in the diets was LA, which was reduced from 42.6 to $30.0 \mathrm{~g} / 100 \mathrm{~g}$ of FA when increasing the level of RCS. Moreover, concentrations of $\alpha$-LNA markedly increased from 9.7 to $25.2 \mathrm{~g} / 100 \mathrm{~g}$ of $\mathrm{FA}$, whereas the concentration of OA decreased from 20.8 to $12.6 \mathrm{~g} / 100$ $\mathrm{g}$ of FA.

\section{FA Composition of Milk}

Sixty-eight individual FA in the milk fat were detected and are presented in Tables 2,3 , and 4 . The proportions of FA with a length between $\mathrm{C} 6: 0$ and $\mathrm{C} 14: 0$ in 
Table 2. Saturated fatty acid (FA) composition of milk fat of cows fed the 4 experimental diets

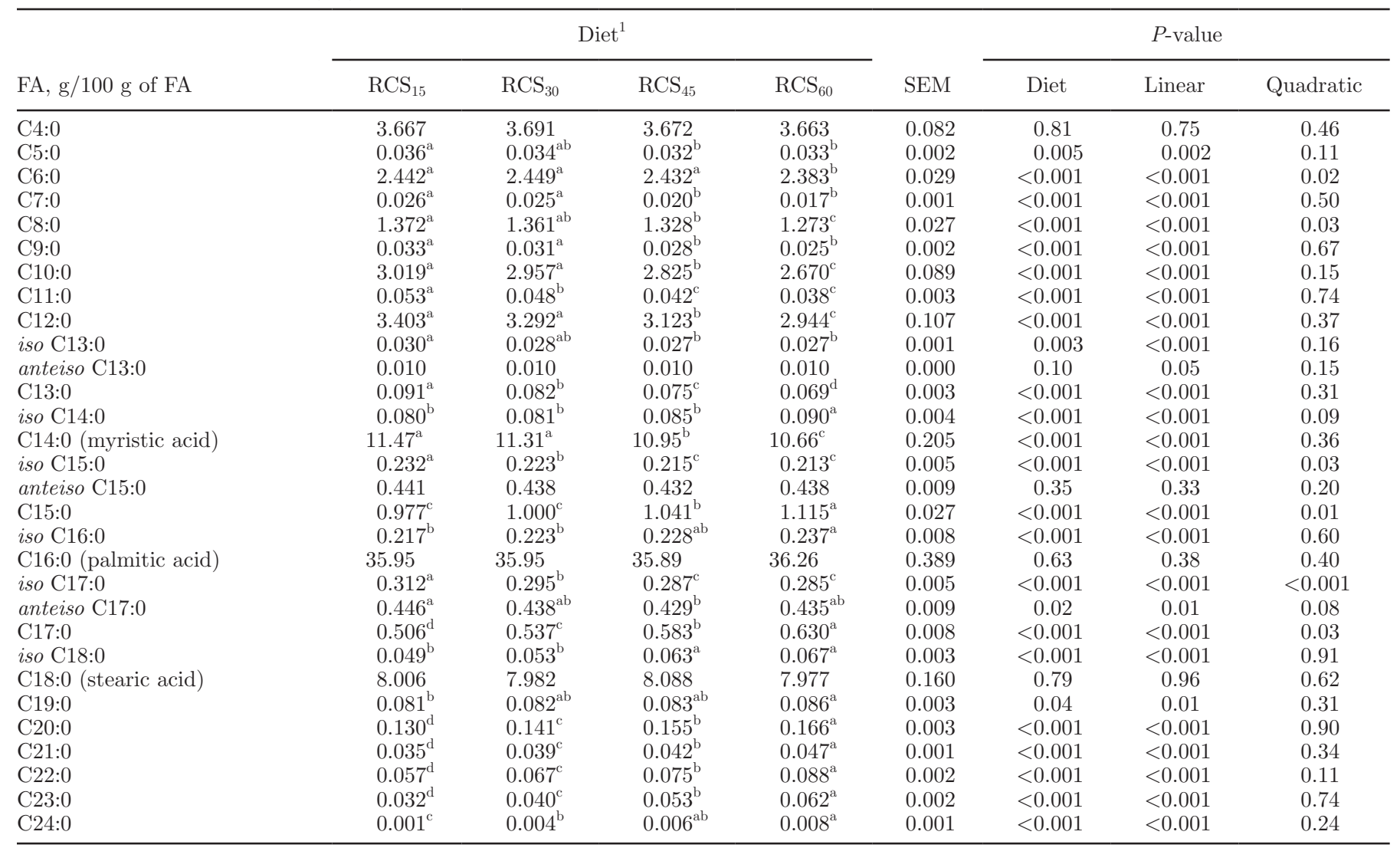

${ }^{\mathrm{a}-\mathrm{d}}$ Least squares means within the same row with different superscripts differ $(P<0.05)$.

${ }^{1}$ Diets were composed of forage and concentrates (75:25), with targeted levels of red clover silage (RCS) in the $\mathrm{TMR}$ of $15 \%\left(\mathrm{RCS}_{15}\right), 30 \%$ $\left(\mathrm{RCS}_{30}\right), 45 \%\left(\mathrm{RCS}_{45}\right)$, and $60 \%\left(\mathrm{RCS}_{60}\right)$ on a DM basis.

milk fat decreased linearly $(P<0.001)$, whereas those between C19:0 and C24:0 increased linearly $(P<0.01)$ with incremental levels of RCS (Table 2). The proportions of palmitic acid (PA, C16:0) and SA (C18:0) were unaffected by diet $(P=0.63$ and 0.79 , respectively) and averaged 36.0 and $8.01 \mathrm{~g} / 100 \mathrm{~g}$ of FA across diets, respectively. The proportions of OA increased linearly $(P=0.003)$ from 15.4 to $16.2 \mathrm{~g} / 100 \mathrm{~g}$ of FA (Table 3$)$. Increasing the level of RCS in the diet had both linear and quadratic $(P<0.001)$ effects on the proportions of VA, which decreased from $0.80\left(\mathrm{RCS}_{15}\right)$ to $0.61 \mathrm{~g} / 100$ $\mathrm{g}$ of FA $\left(\mathrm{RCS}_{60}\right)$.

The proportions of LA (Table 4 ) in milk fat decreased linearly $(P<0.001)$ from 2.06 to $1.98 \mathrm{~g} / 100 \mathrm{~g}$ of $\mathrm{FA}$, whereas those of $\alpha$-LNA were increased linearly $(P<$ 0.001 ) by more than 2 -fold from 0.50 to $1.13 \mathrm{~g} / 100 \mathrm{~g}$ of FA. Increasing the level of RCS in the diet had both linear and quadratic $(P<0.001)$ effects on the proportions of RA, which decreased from $0.37\left(\mathrm{RCS}_{15}\right)$ to 0.28 $\mathrm{g} / 100 \mathrm{~g}$ of FA $\left(\mathrm{RCS}_{60}\right)$. For long-chain PUFA, proportions of ETE and ARA decreased linearly $(P<0.001)$, whereas those of EPA and DPA increased linearly $(P$ $<0.001$ ).

The effects of feeding experimental diets on proportions of important groups of milk FA are shown in Table 5. Increasing the level of RCS decreased linearly $(P<0.001)$ the proportions of SFA from 73.2 to 72.0 $\mathrm{g} / 100 \mathrm{~g}$ of $\mathrm{FA}$, whereas those of PUFA were increased linearly $(P<0.001)$ from 3.94 to $4.41 \mathrm{~g} / 100 \mathrm{~g}$ of FA. As a consequence, the ratio of SFA to UFA in milk fat decreased linearly $(P=0.002)$ from 2.87 to 2.74 . The proportions of MUFA in milk fat remained constant $(P$ $=0.55)$ and averaged $22.0 \mathrm{~g} / 100 \mathrm{~g}$ of FA across diets. The proportions of LCFA in milk fat increased linearly $(P=0.03)$ from 30.88 to $31.74 \mathrm{~g} / 100 \mathrm{~g}$ of $\mathrm{FA}$, whereas the proportions of SCFA were reduced linearly $(P<$ 0.001 ) and MCFA tended to be reduced linearly ( $P$ $=0.06)$. A quadratic effect $(P=0.001)$ was found for BCFA in milk fat, with the lowest proportion of BCFA with diet $\mathrm{RCS}_{45}$ compared with diet $\mathrm{RCS}_{15}$ (1.78 vs. $1.82 \mathrm{~g} / 100 \mathrm{~g}$ FA, $P=0.02)$. The n-3 FA was increased linearly $(P<0.001)$, whereas the $\mathrm{n}-6 \mathrm{FA}$ was reduced 
Table 3. Monounsaturated fatty acid (FA) composition of milk fat of cows fed the 4 experimental diets

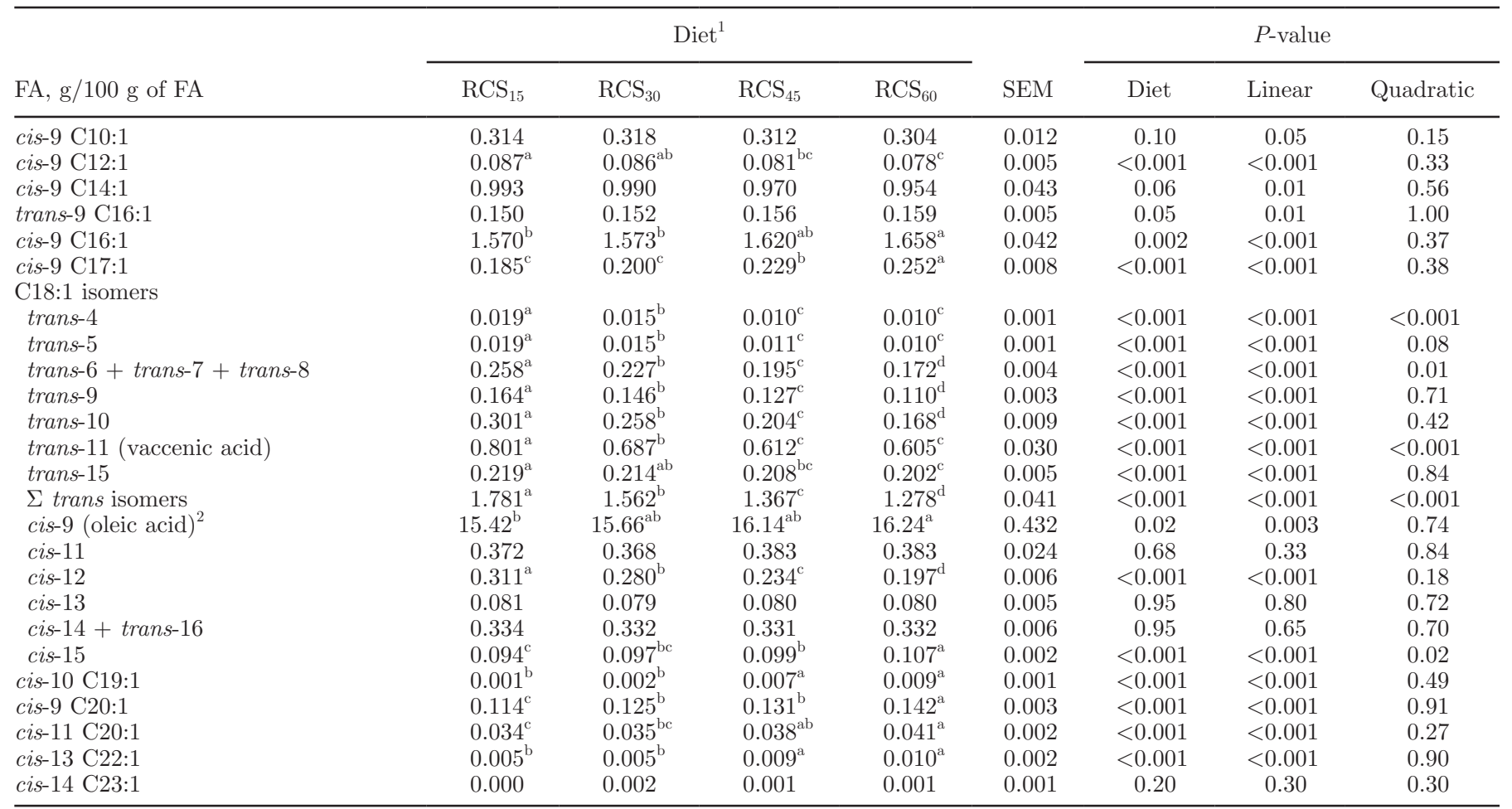

${ }^{\mathrm{a}-\mathrm{d}}$ Least squares means within the same row with different superscripts differ $(P<0.05)$.

${ }^{1}$ Diets were composed of forage and concentrates (75:25), with targeted levels of red clover silage (RCS) in the $\mathrm{TMR}$ of $15 \%\left(\mathrm{RCS}_{15}\right)$, $30 \%$ $\left(\mathrm{RCS}_{30}\right), 45 \%\left(\mathrm{RCS}_{45}\right)$, and $60 \%\left(\mathrm{RCS}_{60}\right)$ on a DM basis.

${ }^{2}$ Includes minor proportions of trans-12 to trans-14 C18:1 (<1.0 g/100 g of FA).

Table 4. Polyunsaturated fatty acid (FA) composition of milk fat of cows fed the 4 experimental diets

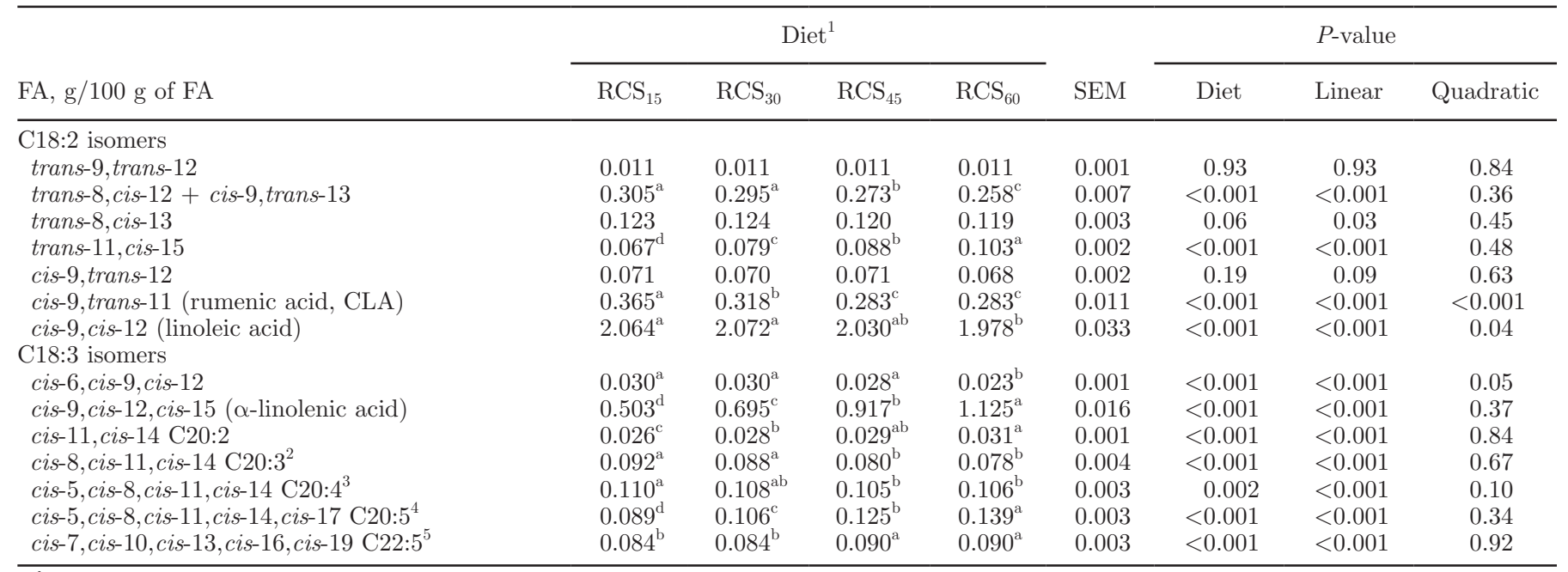

${ }^{\mathrm{a}-\mathrm{d}}$ Least squares means within the same row with different superscripts differ $(P<0.05)$.

${ }^{1}$ Diets were composed of forage and concentrates (75:25), with targeted levels of red clover silage (RCS) in the $\mathrm{TMR}$ of $15 \%\left(\mathrm{RCS}_{15}\right)$, $30 \%$ $\left(\mathrm{RCS}_{30}\right), 45 \%\left(\mathrm{RCS}_{45}\right)$, and $60 \%\left(\mathrm{RCS}_{60}\right)$ on a DM basis.

${ }^{2}$ Eicosatrienoic acid.

${ }^{3}$ Arachidonic acid.

${ }^{4}$ Eicosapentaenoic acid.

${ }^{5}$ Docosapentaenoic acid. 
linearly $(P<0.001)$. Consequently, the $\mathrm{n}-6 / \mathrm{n}-3$ ratio was reduced from 3.44 to 1.66 with both a linear and quadratic effect $(P<0.001)$. For $\Delta^{9}$-desaturase activity, the DA $\mathrm{C} 12$ was equal across $\operatorname{diets}(P=0.56)$. The DA C14 increased linearly $(P=0.02)$ without a diet effects $(P=0.14)$, whereas DA C10 increased linearly $(P<0.001)$ from 0.105 to 0.115 with increasing levels of RCS.

\section{DISCUSSION}

The present study was designed to examine changes in the milk FA profile caused by the replacement of MZS with incremental proportions of RCS in diets maintaining a constant forage-to-concentrate ratio. Along with the replacement of MZS with RCS, soybean meal was replaced with wheat with increasing levels of RCS to achieve isonitrogenous diets. The proportions of soybean meal plus wheat in the diets were $16 \%$ of DM and contributed only approximately $12 \%$ to the dietary ether extract. Consequently, an effect of differences in diet composition on the milk FA profile is predomi- nantly related to the different proportions of RCS and MZS. In general, MZS contains low levels of $\alpha$-LNA and much higher levels of LA and OA compared with red clover (hay or silage; Glasser et al., 2013). Consequently, replacing MZS with RCS in the diet increased the dietary concentrations of $\alpha$-LNA by more than 2 -fold, whereas those of OA and LA were reduced by 39 and $30 \%$, respectively, with $\mathrm{RCS}_{60}$ compared with $\mathrm{RCS}_{15}$.

Dietary lipids undergo extensive transformations in the rumen, which are mainly carried out by the resident bacterial species. The initial step in ruminal lipid metabolism is the hydrolysis of ester linkages found in triglycerides, phospholipids, and glycolipids, resulting in the liberation of free FA. Subsequently, UFA are subjected to $\mathrm{BH}$, a protection mechanism against the toxic effects of PUFA on microbes (Lock and Bauman, 2004). Linoleic acid and $\alpha$-LNA, as the main substrates of $\mathrm{BH}$, are successively isomerized and desaturated to VA and further to SA as the end product (Lock and Bauman, 2004; Shingfield et al., 2010). In the present study, the proportions of LA in milk fat were decreased slightly by

Table 5. Groups of fatty acids (FA) and $\Delta^{9}$-desaturase activity of milk fat of cows fed the 4 experimental diets

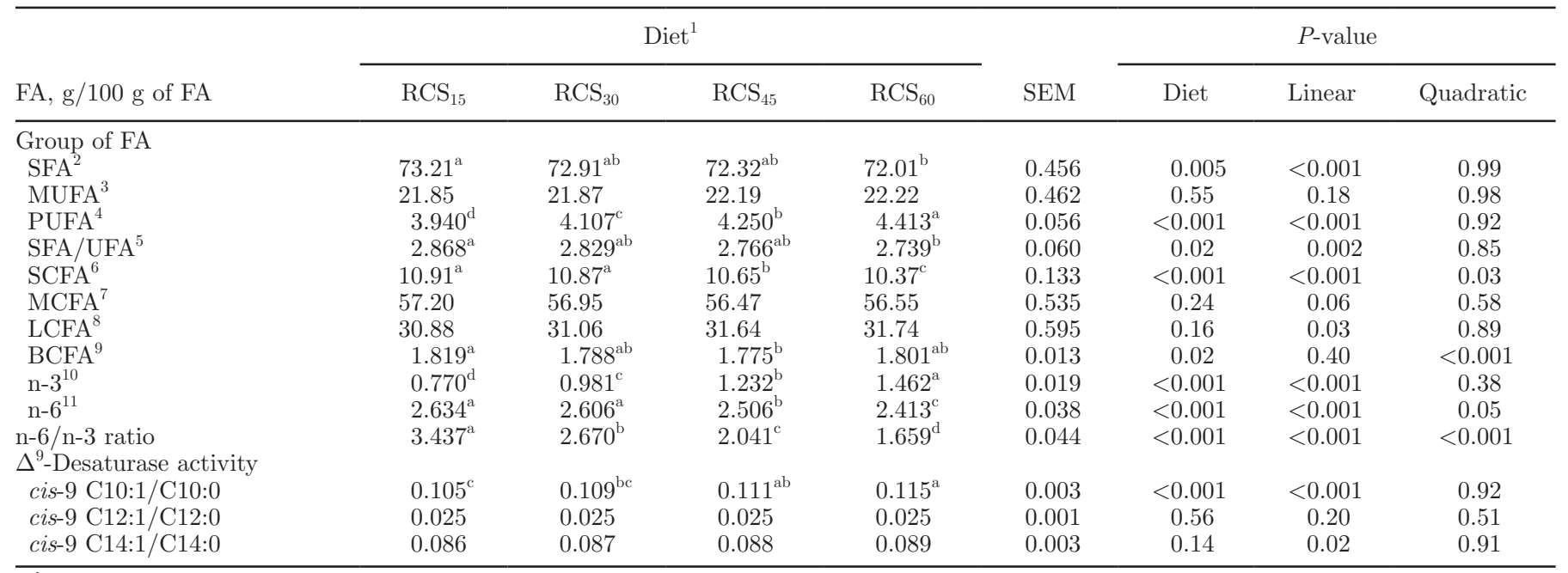

\footnotetext{
${ }^{\mathrm{a}-\mathrm{d}}$ Least squares means within the same row with different superscripts differ $(P<0.05)$.

${ }^{1}$ Diets were composed of forage and concentrates $(75: 25)$, with targeted levels of red clover silage $(\mathrm{RCS})$ in the $\mathrm{TMR}_{\mathrm{N}}$ of $15 \%\left(\mathrm{RCS}_{15}\right), 30 \%$ $\left(\mathrm{RCS}_{30}\right), 45 \%\left(\mathrm{RCS}_{45}\right)$, and $60 \%\left(\mathrm{RCS}_{60}\right)$ on a $\mathrm{DM}$ basis.

${ }^{2}$ Sum of all FA without double bonds.

${ }^{3}$ Sum of all FA with one double bond.

${ }^{4}$ Sum of all FA with more than one double bond.

${ }^{5} \mathrm{UFA}=\mathrm{MUFA}+\mathrm{PUFA}$.

${ }^{6}$ Short-chain FA, C4:0 to C10:0 (includes SFA and UFA).

${ }^{7}$ Medium-chain FA, C11:0 to C17:0 (includes SFA and UFA).

${ }^{8}$ Long-chain FA, C18:0 to C24:0 (includes SFA and UFA).

${ }^{9}$ Branched-chain $\mathrm{FA}$, sum of iso $\mathrm{C} 13: 0$, iso $\mathrm{C} 14: 0$, iso $\mathrm{C} 15: 0$, iso $\mathrm{C} 16: 0$, iso $\mathrm{C} 17: 0$, iso $\mathrm{C} 18: 0$, anteiso $\mathrm{C} 13: 0$, anteiso $\mathrm{C} 15: 0$, and anteiso $\mathrm{C} 17: 0$.

${ }^{10} \mathrm{n}-3 \mathrm{FA}=$ cis-15 C18:1 + cis-9,cis-12,cis-15 C18:3 ( $\alpha$-linolenic acid) + cis-5, cis-8,cis-11,cis-14,cis-17 C20:5 (eicosapentaenoic acid) + cis-7,cis10, cis-13, cis-16, cis-19 C22:5 (docosapentaenoic acid).

${ }^{11} \mathrm{n}-6 \mathrm{FA}=$ cis-12 C18:1 + cis-9,cis-12 C18:2 (linoleic acid) + cis-6,cis-9,cis-12 C18:3 + cis-11,cis-14 C20:2 + cis-8, cis-11,cis-14 C20:3 (eicosatrienoic acid) + cis-5,cis-8, cis-11,cis-14 C20:4 (arachidonic acid).
} 
approximately $4 \%$, whereas those of $\alpha$-LNA were more than doubled when increasing the level of RCS from 15 to $60 \%$ of diet DM. Direct comparison of these results with the literature is not possible because at this date no published results exist on the effects of replacing MZS with RCS on FA profile of milk cows. However, several studies observed increased LA and $\alpha$-LNA concentrations in milk fat of cows when RCS replaced grass silage in the diet (Dewhurst et al., 2003a; Moorby et al., 2009; Halmemies-Beauchet-Filleau et al., 2014). Furthermore, Dewhurst et al. (2003b) and HalmemiesBeauchet-Filleau et al. (2013) reported that ruminal $\mathrm{BH}$ of LA and $\alpha$-LNA was reduced when replacing grass silage with RCS in the diet of cows. The reduction in rumen BH with feeding RCS-based diets is thought to be mediated through an inhibitory effect on lipolysis due to the action of ortho-quinones formed by the enzyme PPO, which is specifically active in red clover (Lee, 2014). Polyphenol oxidase catalyzes the oxidation of endogenous ortho-diphenols to ortho-quinones that quickly react with themselves or crosslink a variety of cellular nucleophiles (e.g., proteins), resulting in the formation of phenol-bound protein complexes (Bittner, 2006; Lee, 2014). Although the exact mechanism for protection of membrane-bound PUFA against lipolysis and subsequent ruminal BH has not yet been fully elucidated, several theories have been suggested. The most likely mechanism for protection of PUFA across the rumen might be the entrapment of glycerol-based lipids within phenol-bound protein complexes, thereby representing a physical barrier to microbial lipases (Van Ranst et al., 2011; Lee, 2014). Moreover, some polar lipids have potential nucleophilic binding sites. It is therefore possible that ortho-quinones directly bind to glycerol-based lipids and, thus, protect them from enzymatic degradation in the rumen (Dewhurst et al., 2006; Van Ranst et al., 2011). Although it has frequently been shown that plant and microbial lipases are deactivated through coupling of ortho-quinones, it is unlikely to have an effect on lipolysis and $\mathrm{BH}$ in the rumen (Lee, 2014). In the present study, the reduction of LA content in the diets was accompanied with a slight reduction of proportions of LA in the milk. However, apparent recovery of LA from feed into milk increased linearly $(P<0.001$, data not presented $)$, suggesting reduced ruminal BH of LA with increasing proportion of RCS in the diets. Additionally, cis- 12 C18:1 concentration in milk was reduced by $37 \%$ with $\mathrm{RCS}_{60}$ compared with $\mathrm{RCS}_{15}$. This metabolite is derived from a minor $\mathrm{BH}$ pathway of LA (Toral et al., 2013); therefore, its reduction may indicate inhibited ruminal BH of LA. Conversely, apparent recovery of $\alpha$-LNA from feed into milk decreased linearly $(P<$ 0.001 , data not presented). Hence, it seems that the increasing proportions of $\alpha$-LNA in milk fat resulted solely from the linear increase in $\alpha$-LNA intake with incremental levels of RCS (from 24.7 to $51.0 \mathrm{~g} / \mathrm{d} ; P$ $<0.001$; data not presented) and not from reduced $\mathrm{BH}$ as expected. Moreover, the main pathway for the $\mathrm{BH}$ of $\alpha$-LNA yields trans-11, cis-15 $\mathrm{C} 18: 2$, which was increased by $54 \%$ with increasing proportions of RCS. The trans-11,cis-15 C18:2 can be further converted to its major isomer (VA) followed by $\mathrm{BH}$ to $\mathrm{SA}$ or can alternatively be hydrogenated to trans-15 C18:1 or cis15 C18:1 (Lock and Bauman, 2004) and both further hydrogenated to SA. Feeding RCS increased proportions of cis-15 C18:1 by $14 \%$ in the milk but reduced those of trans-15 C18:1 by $8 \%$.

In general, these results support partially the hypothesis that dietary RCS inhibits to some extent ruminal $\mathrm{BH}$ of PUFA, but changes of proportions of LA and LNA in the milk and their intermediate metabolites of $\mathrm{BH}$ seem to be more related to their contents in the diets. However, it is difficult to differentiate in the present study whether, or to what extent, reduced $\mathrm{BH}$ due to PPO activity also influenced the increase of $\alpha$-LNA in the milk; therefore, this option cannot be completely excluded. Indeed, Dewhurst et al. (2003a) reported that apparent recoveries of $\alpha$-LNA from feed into milk increased from 4.5 to $5.1 \%$ for grass silagebased diets to about 8.9 to $9.7 \%$ for RCS-based diets, whereas those of LA were unaffected by inclusion of RCS. Similarly, comparing feeding a RCS-grass silage mixture (60:40 on a DM basis) with 3 grass silages, Arvidsson et al. (2012) observed no differences in apparent recoveries of LA and $\alpha$-LNA from feed into milk but reported greater concentration of $\alpha$-LNA and not of LA in milk from cows fed the RCS-grass silage compared with the grass silage diets. Whether reduced $\mathrm{BH}$ influenced the concentration of LA and $\alpha$-LNA in the milk was not clear, but apparent recovery of LA was increased, which is seen as a positive nutritional factor. However, lipolysis and $\mathrm{BH}$ in the rumen might have been influenced by a variety of factors other than the possible effects induced by PPO. Feed retention time in the rumen, and changes in rumen environment and in composition of the microbial population caused by diet composition, can influence $\mathrm{BH}$ pathways as well, thereby leading to substantial changes in FA intermediates produced in the rumen (Lock and Bauman, 2004). Considering the linear decrease in DMI from 22.4 to $19.8 \mathrm{~kg} / \mathrm{d}$ (Schulz et al., 2018), retention time in the rumen might have been prolonged with increasing levels of RCS, thereby increasing the exposure time of forage lipids to lipolysis and $\mathrm{BH}$ of $\alpha$-LNA, which partially explains the reduced apparent recovery of $\alpha$-LNA $(P$ $<0.001$, data not presented). Additionally, increasing the level of RCS decreased the dietary concentration of 
readily fermentable carbohydrates (starch plus sugar) by approximately $31 \%$, which might have affected ruminal $\mathrm{BH}$ through shifts in the microbial community (Loor et al., 2004) despite the indication for maintaining a physiological rumen $\mathrm{pH}$ in all diets (Schulz et al., 2018).

The essential FA for humans are classified into n- 6 and n-3, where n- 6 FA are represented mostly by LA and n-3 FA by $\alpha$-LNA (Simopoulos, 2016). Recent studies in humans showed that in addition to absolute amounts of n- 6 and n- 3 FA intake, the $n-6 / n-3$ ratio is important for human health (Simopoulos, 2016), because an unbalanced ratio in favor of n- 6 PUFA is highly prothrombotic and proinflammatory, which contributes to the prevalence of atherosclerosis, obesity, and diabetes (Simopoulos, 2008), and is involved in the pathogenesis of depression (Husted and Bouzinova, 2016). Thus, increasing n-6 FA (e.g., LA) in milk fat or high n-6/n-3 ratios seem not to be always desirable. In line with this, LA and the sum of n- 6 FA in milk fat were reduced while the sum of n-3 was increased. Consequently, the n-6/n-3 ratios were decreased with increasing RCS in the diets of the cows, which contributed to increasing the nutritional quality of milk fat for humans. In tissues, LA is the precursor of the long-chain PUFA ETE and ARA, whereas $\alpha$-LNA is the precursor of EPA and DPA (Salem et al., 1999). Increasing the level of RCS in the diet decreased linearly the proportion of ETE and ARA in milk fat, whereas those of EPA and DPA increased linearly. Hence, changes in the proportions of long-chain PUFA in milk fat can be explained by a reduced or increased hepatic synthesis due to the availability of their respective precursors, which escaped from ruminal BH. Therefore, differences reflected the differences in intake and proportions in the milk of LA and $\alpha$-LNA between diets. HalmemiesBeauchet-Filleau et al. (2014) reported increased proportions of ETE, ARA, EPA, and DPA in milk of cows when replacing grass silage with RCS in the diet, which might have resulted from increased dietary intake of $\mathrm{LA}$ in combination with reduced ruminal $\mathrm{BH}$ of $\mathrm{LA}$ and $\alpha$-LNA (Halmemies-Beauchet-Filleau et al., 2013). Similarly, Henke et al. (2017) reported increased proportions of ETE, ARA, EPA, and DPA in milk fat of cows due to higher availability of LA and $\alpha$-LNA caused by a reduced ruminal $\mathrm{BH}$ when supplementing cows with quebracho tannin extract.

Ruminal BH of LA results in RA as the first intermediate (Corl et al., 2001), which can be further hydrogenated to VA or may escape ruminal $\mathrm{BH}$ and appear in the milk. Rumenic acid is the predominant CLA isomer in milk and is considered essential for humans (Lock and Bauman, 2004). The proportion of RA in milk was reduced by $22 \%$ when increasing the level of RCS from
15 to $60 \%$ in the diet. However, the second source of $\mathrm{RA}$ is the endogenous synthesis in the mammary gland from ruminally derived VA, which is catalyzed by the enzyme stearoyl coenzyme A desaturase, also called $\Delta^{9}$ desaturase (Corl et al., 2001), and has been estimated to account for 64 to $97 \%$ of the total RA in milk fat (Griinari et al., 2000; Shingfield et al., 2010). Therefore, increasing the rumen outflow of VA is thought to be the key factor for enhancing the milk fat content of RA (Lock and Bauman, 2004). Nevertheless, the proportion of VA in milk fat - a FA that reduced the risk for atherosclerosis in humans (Lock et al., 2005) - was also reduced by $24 \%$ when increasing the level of RCS. Moreover, related to $\Delta^{9}$-desaturase indicators, DA C12 was not affected by diets, and DA C10 and DA C14 were increased with increasing proportions of RCS in the diets. Consequently, the $\Delta^{9}$-desaturase activity does not account for the change of RA proportion in the milk fat. Therefore, the reduction of VA proportion in the milk was probably the most important driving factor for the reduction of RA, which might be due to a reduction in ruminal $\mathrm{BH}$ of LA and $\alpha$-LNA and, most probable, due to the linear decrease in the intake of LA and $\alpha$-LNA (from 133 to $112 \mathrm{~g} / \mathrm{d} ; P<0.001$; data not presented) when increasing levels of RCS in the diet.

Oleic acid is the main MUFA in milk fat, and enhancing its concentration in milk is desirable, because $\mathrm{OA}$ is recognized to reduce the risk for cardiovascular diseases (Dewhurst et al., 2006). In the present study, the proportion of OA in milk fat increased linearly with incremental levels of RCS. Similar results, although comparing RCS with grass silage, were reported by Moorby et al. (2009). During FA analysis, OA coeluted with trans-12 to trans-14 C18:1, which led to a slight overestimation of OA by $2.5 \%$ (Precht and Molkentin, 1996), based on an average milk fat composition $(<1.0$ $\mathrm{g} / 100 \mathrm{~g}$ of FA). Overall, however, the changes observed for OA in our study are clearly not due to the variation of the trans-12 to trans-14 C18:1 fraction. Hence, the overlap should not significantly impair the OA findings. Oleic acid in milk fat originates, at least in part, directly from the diet (Palmquist, 2006). Halmemies-BeauchetFilleau et al. (2013) reported that apparent ruminal $\mathrm{BH}$ of $\mathrm{OA}$ in lactating cows tended to decrease linearly from 59 to $54 \%$ when replacing grass silage with RCS in the diet. Hence, it should be noted that the enrichment of OA in milk fat in our study occurred, although the dietary concentration of OA decreased (39\%), which may indicate an inhibition of the ruminal $\mathrm{BH}$ of $\mathrm{OA}$ when increasing the level of RCS in the diet. Moreover, approximately $60 \%$ of the OA secreted in milk is synthesized from SA in the mammary gland (Shingfield et al., 2010), which is based on the introduction of a cis double bond between $\mathrm{C} 9$ and $\mathrm{C} 10$ and is catalyzed 
by $\Delta^{9}$-desaturase (Henke et al., 2017). The DA of C10 and $\mathrm{C} 14$ were increased with incremental levels of RCS in the diet, which suggest an increased $\Delta^{9}$-desaturase activity and an increased endogenous synthesis of OA. Nevertheless, at this point, differences in DA indicators were quite small, and they are generally only a proxy of $\Delta^{9}$-desaturase activity. Therefore, extrapolating the results of these indicators of $\Delta^{9}$-desaturase activity has to be done with caution. Additionally, OA is the most predominant FA in ruminant adipose tissue that can be mobilized during a negative energy balance, resulting in increased proportions of MUFA in the milk (Jakobsen, 1999). Holstermann (2012) reported that lactating cows mobilized body fat from calving until a brake-point of $99 \pm 5$ DIM, and LCFA stabilized to a mean proportion of $39 \pm 0.5 \mathrm{~g} / 100 \mathrm{~g}$ of FA in the milk. The cows of the present study were between middle and late lactation and gaining weight, the proportion of LCFA in milk averaged $31 \pm 0.4 \mathrm{~g} / 100 \mathrm{~g}$ of FA during the whole experiment, and the proportions of MUFA remained similar across diets. The latter suggests that a possible contribution of adipose tissue mobilization to OA in milk can be disregarded. Stearic acid is also a predominant $\mathrm{FA}$ stored in body fat of ruminants (Chilliard and Ferlay, 2004). In the present study, SA proportions in milk remained constant with increasing level of RCS, which can confirm again that adipose tissue of cows was not mobilized. Because VA proportions were reduced, the SA proportions in the milk were expected to be reduced as well. Stearic acid proportion was slightly increased in the diet by $5 \%$ with increasing proportions of RCS, which probably compensated the expected reduced synthesis of SA from VA in the rumen. However, no changes of SA proportions in the milk is not surprising because of its desaturation to OA in the mammary gland (Jakobsen, 1999).

Increasing the level of RCS from $\mathrm{RCS}_{15}$ to $\mathrm{RCS}_{60}$ in the diet resulted in a linear increase in the proportions of total PUFA by $12 \%$ in milk fat, whereas those of SFA and MUFA were reduced linearly and remained constant, respectively. Across diets, no changes, increases or decreases of concentrations of individual PUFA, were observed, but the magnitude of these changes was small. Interestingly, $\alpha$-LNA and its products (EPA and DPA) increased by 0.63 and $0.11 \mathrm{~g} / 100 \mathrm{~g}$ of FA, respectively, which accounted for most of the contribution to the total increase of total PUFA with increasing proportion of RCS. Replacing MZS with RCS in the diet did not affect proportions of $\mathrm{C} 4: 0$ and decreased linearly those of C6:0 to C12:0. Similarly, Halmemies-Beauchet-Filleau et al. (2014) reported reduced proportions of C4:0 to C8:0, MA, and PA when replacing grass silage with RCS. Myristic acid, which is recognized to increase high- density lipoprotein level in plasma in humans (Dabadie et al., 2005) and associated with reduced atherosclerosis when considering moderate intakes, was reduced linearly in our study. The concentration of PA, which is known to increase plasma cholesterol in humans (Yu et al., 1995) and is related to decreased insulin sensitivity (Bermudez et al., 2014), was not affected. Other studies reported that RCS decreases proportions of MA and PA in milk fat (Dewhurst et al., 2003a; Moorby et al., 2009), whereas Dewhurst et al. (2003b) found no effects in a second experiment. For all these FA, de novo synthesis accounts for all C4:0 to C12:0, 95\% of C14:0, and $50 \%$ of C16:0 secreted in milk fat, using acetate and 3-hydroxy-butyrate as substrates (Shingfield et al., 2010). However, in our study proportions of VFA in the rumen were not measured.

According to Shingfield et al. (2010), LCFA (C $\geq 16$ ) inhibit de novo synthesis of SCFA and MCFA in the mammary gland of cows, with effects being stronger for FA with longer carbon chains or higher degree of saturation. In the present study, proportions of LCFA were increased linearly, proportions of SCFA decreased linearly, and proportions of MCFA tended to be reduced linearly with increasing levels of RCS. The latter was probably due to inhibition of de novo synthesis by increased proportions of $\mathrm{C} 19: 0$ to $\mathrm{C} 24: 0$ and total PUFA in the milk. Moreover, RCS level did not have an effect on proportions of SA concentrations, which is regarded as neutral in its effect on plasma cholesterol in humans (Yu et al., 1995) and most recently was suggested to have protective effects with regard to cardiovascular disease risk (Hunter et al., 2010). The BCFA concentration in milk is largely derived from rumen bacteria and is therefore an important marker of rumen function and microbial synthesis (Fievez et al., 2012). Moreover, BCFA were proved to possess anticarcinogenic properties (Yang et al., 2000; Wongtangtintharn et al., 2004) and showed similar cytotoxicity as CLA (Lock and Bauman, 2004). In the present study, increasing the proportions of RCS plus wheat in the diet reduced quadratically the proportions of BCFA in the milk fat, and the proportion of BCFA when feeding diet $\mathrm{RCS}_{45}$ was reduced by $2.4 \%$ compared with diet $\mathrm{RCS}_{15}$. However, the magnitude of this reduction was small, which reflects no substantial negative effects on the nutritional quality of milk fat in human diets.

Overall, increasing the level of RCS at the expense of MZS has the potential to increase to some extent the nutritional quality of milk fat for humans by increasing the proportions of $\alpha$-LNA, EPA, DPA, total PUFA, and OA; by reducing SFA; and by decreasing $n-6 / n-3$ ratio. Feeding strategies attempting to improve nutritional quality of ruminant products should be executed 
only when negative effects on any other animal's traits are excluded (Henke et al., 2017). Unfortunately, the favorable changes in milk FA profile were counteracted by the decreased proportions of other FA that are regarded as beneficial to human health (i.e., LA, ETE, ARA, RA, and VA) when increasing the level of RCS. Moreover, considering that incremental levels of RCS had detrimental effects on DMI, milk yield, and milk protein content (Schulz et al., 2018), the RCS proportion in the diets for high-yielding dairy cows must be restricted, leading to a limited potential of RCS to modify the milk FA profile.

\section{CONCLUSIONS}

Increasing the level of RCS at the expense of MZS resulted in changes in the FA profile of milk fat, which were predominantly caused by differences in FA supply by the diet. On one hand, incremental proportions of RCS increased the proportions of total PUFA and especially of $\alpha$-LNA, and reduced the $n-6 / n-3$ ratio, which are favorable from a human health point of view. On the other hand, proportions of LA, cis-9,trans-11 CLA (RA), and VA in milk fat decreased with increasing levels of RCS, which outweighed the benefits. Feeding RCS represents an interesting strategy to increase intake of $\alpha$-LNA in dairy cows. Hence, further research is still needed to evaluate the use of RCS in combination with MZS as an alternative nutritional strategy to create a milk FA profile that is considered more desirable for human health.

\section{ACKNOWLEDGMENTS}

This study was funded by the Federal Ministry of Education and Research within the research project "Food Chain Plus" (project number 0315538A; 20102015). Skillful technical assistance and care of the experimental animals by the personnel of the experimental farm Schädtbek of the Max Rubner-Institute is highly appreciated. Furthermore, many thanks are extended to Ann-Kristin Licht and Gwendolyn Keinarth of the Institute of Animal Nutrition and Physiology of the Christian-Albrechts-Universität zu Kiel (Kiel, Germany) for help during the feeding experiment. The authors are very grateful for the valuable laboratory work of Annette Hollmann and Monika Paschke-Beese of the Institute of Animal Nutrition and Physiology of the Christian-Albrechts-Universität zu Kiel and Melanie Selk of the Max Rubner-Institute (Kiel, Germany). The authors acknowledge Mario Hasler of the Lehrfach Variationsstatistik of the Christian-Albrechts-Universität zu Kiel for statistical advice.

\section{REFERENCES}

Arvidsson, K., A.-M. Gustavsson, V. Fievez, and K. Martinsson. 2012. The effect of N-fertilisation rate or inclusion of red clover to timothy leys on fatty acid composition in milk of dairy cows fed a commercial silage:concentrate ratio. Animal 6:1178-1186.

Bauman, D. E., and J. M. Griinari. 2003. Nutritional regulation of milk fat synthesis. Annu. Rev. Nutr. 23:203-227.

Bermudez, B., A. Ortega-Gomez, L. M. Varela, J. Villar, R. Abia, F. J. Muriana, and S. Lopez. 2014. Clustering effects on postprandial insulin secretion and sensitivity in response to meals with different fatty acid compositions. Food Funct. 5:1374-1380.

Bittner, S. 2006. When quinones meet amino acids: Chemical, physical and biological consequences. Amino Acids 30:205-224.

Broderick, G. A.. R. P. Walgenbach, and S. Maignan. 2001. Production of lactating dairy cows fed alfalfa or red clover silage at equal dry matter or crude protein contents in the diet. J. Dairy Sci. 84:1728-1737

Castro-Montoya, J., A. Henke, J. Molkentin, K. Knappstein, A. Susenbeth, and U. Dickhoefer. 2016. Relationship between milk odd and branched-chain fatty acids and urinary purine derivatives in dairy cows supplemented with quebracho tannins - A study to test milk fatty acids as predictors of rumen microbial protein synthesis. Anim. Feed Sci. Technol. 214:22-33.

Chilliard, Y., and A. Ferlay. 2004. Dietary lipids and forages interactions on cow and goat milk fatty acid composition and sensory properties. Reprod. Nutr. Dev. 44:467-492.

Corl, B. A., L. H. Baumgard, D. A. Dwyer, J. M. Griinari, B. S. Philips, and D. E. Bauman. 2001. The role of $\Delta^{9}$-desaturase in the production of cis-9, trans-11 CLA. J. Nutr. Biochem. 12:622-630.

Dabadie, H., E. Peuchant, M. Bernard, P. Leruyet, and F. Mendy. 2005. Moderate intake of myristic acid in sn-2 position has beneficial lipid effects and enhances DHA of cholesteryl esters in an interventional study. J. Nutr. Biochem. 16:375-382.

Dewhurst, R. J., R. T. Evans, N. D. Scollan, J. M. Moorby, R. J. Merry, and R. J. Wilkins. 2003a. Comparison of grass and legume silages for milk production. 1. Production responses with different levels of concentrate. J. Dairy Sci. 86:2598-2611.

Dewhurst, R. J., R. T. Evans, N. D. Scollan, J. M. Moorby, R. J. Merry, and R. J. Wilkins. 2003b. Comparison of grass and legume silages for milk production. 2 . In vivo and in sacco evaluations of rumen function. J. Dairy Sci. 86:2612-2621.

Dewhurst, R. J., K. J. Shingfield, M. R. F. Lee, and N. D. Scollan. 2006. Increasing the concentrations of beneficial polyunsaturated fatty acids in milk produced by dairy cows in high-forage systems. Anim. Feed Sci. Technol. 131:168-206.

DGF (Deutsche Gesellschaft für Fettwissenschaft). 2015. Deutsche Einheitsmethoden zur Untersuchung von Fetten, Fettprodukten, Tensiden und verwandten Stoffen. Wissenschaftliche Verlagsgesellschaft mbH, Stuttgart, Germany.

Federal Republic of Germany. 2014. Tierschutzgesetz. Accessed Dec. 17, 2014. https://www.gesetze-im-internet.de/tierschg/ BJNR012770972.html.

Fievez, V., E. Colman, J. M. Castro-Montoya, I. Stefanov, and B. Vlaeminck. 2012. Milk odd- and branched-chain fatty acids as biomarkers of rumen function-An update. Anim. Feed Sci. Technol. $172: 51-65$

Glasser, F., M. Doreau, G. Maxin, and R. Baumont. 2013. Fat and fatty acid content of forages: A meta-analysis. Anim. Feed Sci. Technol. 185:19-34.

Griinari, J. M., B. A. Corl, S. H. Lacy, P. Y. Chouinard, K. V. V. Nurmela, and D. E. Bauman. 2000. Conjugated linoleic acid is synthesized endogenously in lactating dairy cows by $\Delta^{9}$-desaturase. J. Nutr. 130:2285-2291.

Halmemies-Beauchet-Filleau, A., A. Vanhatalo, V. Toivonen, T. Heikkilä, M. R. F. Lee, and K. J. Shingfield. 2013. Effect of replacing grass silage with red clover silage on ruminal lipid metabolism in lactating cows fed diets containing a 60:40 forage-to-concentrate ratio. J. Dairy Sci. 96:5882-5900.

Halmemies-Beauchet-Filleau, A., A. Vanhatalo, V. Toivonen, T. Heikkilä, M. R. F. Lee, and K. J. Shingfield. 2014. Effect of replacing 
grass silage with red clover silage on nutrient digestion, nitrogen metabolism, and milk fat composition in lactating cows fed diets containing a 60:40 forage-to-concentrate ratio. J. Dairy Sci. 97:3761-3776.

Henke, A., E. Westreicher-Kristen, J. Molkentin, U. Dickhoefer, K. Knappstein, M. Hasler, and A. Susenbeth. 2017. Effect of dietary quebracho tannin extract on milk fatty acid composition in cows. J. Dairy Sci. 100:6229-6238.

Hoffman, P. C., and L. M. Bauman. 2003. Strategies to improve milk yield of lactating dairy cows fed red clover silage. Prof. Anim. Sci. 19:178-187.

Holstermann, M. D. 2012. Änderungen des Fettsäuremusters und der $\delta^{13} \mathrm{C}$-Werte im Milchfett als Indikator für die Körperfettmobilisierung bei Kühen. Dissertation. Christian-Albrechts-Universität, Kiel, Germany.

Hunter, J. E., J. Zhang, and P. M. Kris-Etherton. 2010. Cardiovascular disease risk of dietary stearic acid compared with trans, other saturated, and unsaturated fatty acids: A systematic review. Am. J. Clin. Nutr. 91:46-63.

Husted, K. S., and E. V. Bouzinova. 2016. The importance of n6/n-3 fatty acids ratio in the major depressive disorder. Medicina (Kaunas) 52:139-147.

IDF. 2002a. Milk Fat-Preparation of Fatty Acid Methyl Esters: ISO 15884-IDF 182. Int. Dairy Fed., Brussels, Belgium.

IDF. 2002b. Milk Fat-Determination of the Fatty Acid Composition By Gas-Liquid Chromatography: ISO 15885-IDF 184. Int. Dairy Fed., Brussels, Belgium.

IDF. 2010. Milk-Determination of Fat Content-Gravimetric Method (Reference Method): ISO 1211-IDF 1. Int. Dairy Fed., Brussels, Belgium.

Jakobsen, K. 1999. Dietary modifications of animal fat: Status and future perspectives. Fett/Lipid 101:475-483.

Lee, M. R. F. 2014. Forage polyphenol oxidase and ruminant livestock nutrition. Front. Plant Sci. 5:694.

Lock, A. L., and D. E. Bauman. 2004. Modifying milk fat composition of dairy cows to enhance fatty acids beneficial to human health. Lipids 39:1197-1206.

Lock, A. L., C. M. Horne, D. E. Bauman, and A. M. Salter. 2005 Butter naturally enriched in conjugated linoleic acid and vaccenic acid alters tissue fatty acids and improves the plasma lipoprotein profile in cholesterol-fed hamsters. J. Nutr. 135:1934-1939.

Loor, J. J., K. Ueda, A. Ferlay, Y. Chilliard, and M. Doreau. 2004. Biohydrogenation, duodenal flow and intestinal digestibility of trans fatty acids and conjugated linoleic acids in response to dietary forage:concentrate ratio and linseed oil in dairy cows. J. Dairy Sci. 87:2472-2485.
Moorby, J. M., N. M. Ellis, and D. R. Davies. 2016. Assessment of dietary ratios of red clover and corn silages on milk production and milk quality in dairy cows. J. Dairy Sci. 99:7982-7992.

Moorby, J. M., M. R. F. Lee, D. R. Davies, E. J. Kim, G. R. Nute, N. M. Ellis, and N. D. Scollan. 2009. Assessment of dietary ratios of red clover and grass silages on milk production and milk quality in dairy cows. J. Dairy Sci. 92:1148-1160.

Palmquist, D. L. 2006. Milk fat: Origin of fatty acids and influence of nutritional factors thereon. Pages 43-92 in Advanced Dairy Chemistry. Vol. 2: Lipids. 3rd ed. P. F. Fox and P. L. H. McSweeney, ed. Springer, New York, NY.

Precht, D., and J. Molkentin. 1996. Rapid analysis of the isomers of trans-octadecenoic acid in milk fat. Int. Dairy J. 6:791-809.

Salem, N., Jr., R. Pawlosky, B. Wegher, and J. Hibbeln. 1999. In vivo conversion of linoleic acid to arachidonic acid in human adults. Prostaglandins Leukot. Essent. Fatty Acids 60:407-410.

Schulz, F., E. Westreicher-Kristen, K. Knappstein, J. Molkentin, and A. Susenbeth. 2018. Replacing maize silage plus soybean meal with red clover silage plus wheat in diets for lactating dairy cows. J. Dairy Sci. 101:1216-1226.

Shingfield, K., L. Bernard, C. Leroux, and Y. Chilliard. 2010. Role of trans fatty acids in the nutritional regulation of mammary lipogenesis in ruminants. Animal 4:1140-1166.

Simopoulos, A. P. 2008. The importance of the omega-6/omega-3 fatty acid ratio in cardiovascular disease and other chronic diseases. Exp. Biol. Med. (Maywood) 233:674-688.

Simopoulos, A. P. 2016. An increase in the omega-6/omega-3 fatty acid ratio increases the risk for obesity. Nutrients 8:128.

Toral, P., G. Hervás, A. Belenguer, E. Bichi, and P. Frutos. 2013. Effect of the inclusion of quebracho tannins in a diet rich in linoleic acid on milk fatty acid composition in dairy ewes. J. Dairy Sci. 96:431-439.

Van Ranst, G., M. R. F. Lee, and V. Fievez. 2011. Red clover polyphenol oxidase and lipid metabolism. Animal 5:512-521.

Wongtangtintharn, S., H. Oku, H. Iwasaki, and T. Toda. 2004. Effect of branched-chain fatty acids on fatty acid biosynthesis of human breast cancer cells. J. Nutr. Sci. Vitaminol. (Tokyo) 50:137-143.

Yang, Z., S. Liu, X. Chen, H. Chen, M. Huang, and J. Zheng. 2000. Induction of apoptotic cell death and in vivo growth inhibition of human cancer cells by a saturated branched-chain fatty acid, 13-methyltetradecanoic acid. Cancer Res. 60:505-509.

Yu, S., J. Derr, T. D. Etherton, and P. M. Kris-Etherton. 1995. Plasma cholesterol-predictive equations demonstrate that stearic acid is neutral and monounsaturated fatty acids are hypocholesterolemic. Am. J. Clin. Nutr. 61:1129-1139. 